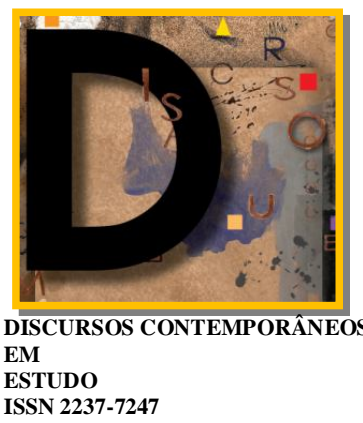

\title{
ENTRELUGARES: O PROFESSOR UNIVERSITÁRIO FRENTE ÀS NOVAS TECNOLOGIAS DE ENSINO
}

Eni Abadia Batista $(U n B)^{1}$

Este artigo apresenta reflexões acerca das práticas discursivas que incidem na constituição da identidade do docente universitário frente às competências exigidas para o uso das novas tecnologias no ensino superior. Tal discussão nasce do exame de diálogos como parte das práticas sociais, dentro do enquadre de Fairclough (2001). Com as transformações que ocorrem no mundo, é natural que se adote uma nova forma de produzir a vida social, o que, consequentemente, gera também novas concepções dos sujeitos envolvidos no processo de ensino. São mudanças que se refletem na individualização das referências, determinando o que Bhabha (1998) chama de "entrelugares." A questão do sujeito está fundamentada na Teoria Social do Discurso de Fairclough (2001), que defende a mobilidade das identidades, conforme o momento da prática social - os sujeitos sociais são moldados pelas práticas discursivas, mas são também capazes de remodelar essas práticas. Para a análise, optou-se pela seleção de recortes de entrevista realizada com professores do curso de Letras e pela observação de eventos discursivos em situação de utilização das novas tecnologias de ensino para desenvolvimento das atividades que compõem as disciplinas.

Palavras-chave: Entrelugares. Discurso. Tecnologias de ensino. Identidade.

This article presents reflections concerning the practical discoursive that happen in the constitution of the identity of the university professor, in front of the demand for the use of new technologies in superior education. Such quarrel is born of the examination of practical dialogues as part of the social ones, inside of fits of Fairclough (2001). With the transformations that occur in the world, it is natural that one adopts a new form to produce social life, that consequently generate also new conceptions of the involved citizens in the education process. These are changes that reflect in the individualization of the references, determining what Bhabha (1998) calls "between places." The question of the identity is based on the Social Theory of the Speech of Fairclough (the 2001), who defends the mobility of the identities, according to the social practical moment - that is, social citizens are molded by the practical discursive, but they are also capable to remodel these practical. The methodology, of qualitative character, was opted to the clipping election of interview carried through with professors of the course of Letters and observation of discursive events in situation of use of the new technologies of education for development of the activities that compose the discipline.

Keywords: Between places. Discourse. Education Technologies. Identity.

\footnotetext{
${ }^{1}$ Doutoranda em Linguística (UnB); membro da ABRALIN; desenvolve pesquisas acadêmicas em Análise de Discurso Crítica e identidades sociais. E-mail: eniabatista@yahoo.com.br.
} 


\section{Primeiras reflexões}

Em consonância com o pensamento de Fairclough (1989), a escolha pelo tema deve-se ao interesse pelos estudos que envolvem o sujeito social. Espera-se que esse tipo de tema possa contribuir para estudos acerca dos possíveis efeitos sobrevindos de discursos recorrentes em contextos sociais. Buscando provocar reflexões quanto à necessidade de superação das relações assimétricas de poder, sustentadas por discursos formulados ideologicamente nas instituições de ensino, este artigo tem a ousada intenção de desvelar as relações de dominação cristalizadas nesse ambiente e cumprir o compromisso ético de apresentar propostas para o fortalecimento das interações, estabelecendo transformações.

Embasam este percurso os pressupostos teóricos proclamados por Fairclough (2001 e 2003a), que aproxima discurso e contextos sociais, e nos estudos de Bhabha (2003), que conceitua situações de mudança como determinantes de incerteza e insegurança - os entrelugares. Segundo Fairclough (2001), as identidades movem-se com as práticas sociais e transpõem fronteiras, constituindo, assim, outras identidades e estabelecendo novos significados. Esse delineamento fornece argumentos para que se ouse assinalar a identidade do professor frente ao impacto causado pela exigência de utilização de novas tecnologias no ensino.

\section{Entrelugares: impacto da transição cultural nas práticas de ensino}

O desenvolvimento cultural traz, de forma acelerada, invenções de diferentes recursos tecnológicos para os mais variados campos de necessidades profissionais, inclusive o educacional. Isso não é um fato novo, mas existem aspectos de grande relevância, pois são interações e transformações ocorridas com sujeitos envolvidos no processo de ensino, colaborando com as interferências no contexto social. Nesse aspecto, Foucault (1982), citado por Silva (2002), defende que os discursos são concebidos "particularmente no interior das instituições de ensino como uma técnica de poder", pois

educar é sujeitar professores e alunos a poderosas técnicas hierárquicas de vigilância, exame e avaliação (por parte de administradores, pais e, de forma não mais importante, colegas) que os constituem como objetos de conhecimento e sujeitos que conhecem. O conhecimento é produzido à medida que os professores extraem ou provocam a ação dos alunos (e vice-versa) e depende das relações de poder através das quais os sujeitos são constituídos (FOUCAULT apud SILVA, 2002, p.103). 
Essa reflexão, segundo Silva (2002, p. 105), "remete às concepções modernistas naturalizadas de educação que oscilam entre o pessoal e o social, o eu e o outro." Entender esse processo requer a compreensão de que a educação está condicionada à aprendizagem contínua. Isso induz à tarefa, sugerida por Foucault (1982), de descobrir e de recusar o que somos, de imaginar e de construir o que poderíamos ser para promover novas formas de subjetividade, criando, nas pessoas, um vazio interno que precisa ser preenchido.

Essas impressões também são decorrentes do desenvolvimento acelerado, que estabelece o uso das novas tecnologias para o ensino. É um estágio necessário no atual contexto social e tem provocado mudanças nas interações sociais e, consequentemente, na constituição da identidade do professor e do aluno. O desenvolvimento tecnológico por si só necessita de mudança de práticas sociais e culturais, exigindo novos modos de ação dos envolvidos no processo. Isso, segundo Bhabha (1998), requer um novo sujeito; um sujeito que se encontra em uma fronteira do presente; um sujeito que não abandonou o passado, mas está imbuído de uma sensação de desorientação, de um distúrbio de direção; um sujeito que capta tão bem aqui e lá; um sujeito que se situa entrelugares.

Nessa concepção, afirma Bhabha, o afastamento das singularidades como categorias conceituais e organizacionais básicas resulta em uma nova posição do sujeito, que habita sem qualquer pretensão a identidade do mundo moderno. Quanto a essa questão de identidade, assegura o autor, o que esse sujeito considera ser teoricamente inovador e politicamente crucial é a necessidade de passar além das narrativas de subjetividades originárias ou iniciais e focalizar os entrelugares, ou seja, os processos que são produzidos na articulação entre as diferenças culturais. Assim, esses entrelugares fornecem espaço para a elaboração de estratégias e características de subjetividade para se reencenar o passado e, ao mesmo tempo, introduzem inovações culturais. Ocorrem aí, segundo Bhabha, os embates de fronteira acerca da diferença que apresentam, tanto a possibilidade de serem consensuais quanto conflituosos, podendo confundir as definições de tradição e de adesão à modernidade.

O professor, sujeito desta pesquisa, depara-se com as mudanças dos meios de ensino e com o uso dos recursos tecnológicos que exigem nova forma de ensinar e de aprender. Surge, nesse momento, um impacto, um estranhamento, pois professor e aluno não mais partilham uma situação de espaço temporal comum. Aquele tenta compreender, sem preparo prévio, que essa é uma prática da atualidade que não poderia ficar longe das instituições de ensino superior. A faculdade, então, estabelece, por sua vez, em novo contexto sociocultural e adota, de forma súbita, as novas formas de interação e de práticas de ensino no lugar daquela em que professores, alunos e toda a comunidade acadêmica estavam rotineiramente engajados na recepção das informações mediadas em uma sala de aula comum. Surge, assim, um novo espaço de transição, 
e é esse que Bhabha considera crucial para a constituição de um novo sujeito, que, segundo o autor, transita no "entrelugar".

Com esse mesmo pensamento, Augé (2005) faz alusão a alguns autores eminentemente representativos para a modernidade, mergulha em reminiscências e enfatiza a aparente desordem presente no imaginário de um escritor que, porventura, ao escrever sobre o moderno, mostra, em sua nova criação, que não esquece as figuras pré-modernas. Mesmo que delas se liberte, segundo a sua concepção, as imagens do passado permanecem, mas são colocadas em outro plano. Auge completa:

Se um lugar pode se definir como identitário, relacional e histórico, um espaço que não se pode definir nem como identitário, nem como histórico, nem como relacional, é um não lugar (...) o lugar e o não lugar são polaridades fugidias: o primeiro nunca é completamente apagado e o segundo nunca se realiza totalmente (AUGÉ, 2005, p. 73).

O espaço do "não lugar", segundo Augé, "não cria nem identidade singular, nem relação, mas solidão e semelhança". Argumenta que os "não-lugares" são essencialmente esses espaços vazios, de solidão, nos quais a sobremodernidade não pode aspirar às mesmas ambições que a modernidade. Dessa forma, realiza-se uma espécie de antropologia do quotidiano em que esses espaços são de anonimato. Tendo em consideração as realidades concretas do mundo atual, os lugares e os não lugares emaranham-se, interpenetram-se, opõem-se. Suas observações são baseadas nesses três aspectos e nas representações individuais, que, para o estudioso, são necessariamente representações de vínculo social, condição substancial na constituição de identidades. Nesse sentido, o sujeito identifica-se com a sociedade a que pertence não só em suas diversas dimensões, mas também em uma individualidade de síntese, expressão de uma cultura própria considerada como um todo. Enquanto isso, deixa de pensar a individualidade absoluta.

Da mesma forma, Bhabha (1998) defende que a nossa existência, atualmente, é marcada por uma tenebrosa sensação de sobrevivência e que nos encontramos nas fronteiras do presente para as quais não parece haver nome próprio, além do prefixo pós, que é considerado atual pelo uso constante, como no caso da expressão pós-modernidade. Segundo Bhabha, "além” não é nem um novo horizonte, nem um abandono ao passado, mas provoca uma sensação de movimento incessante e, nesse movimento, constitui sujeitos nos entrelugares. Nessa condição, resulta a subjetividade na posição do sujeito que habita qualquer pretensão à identidade do mundo moderno e esse sujeito, segundo Bhabha (1998 e 2003), desafia as expectativas normativas de desenvolvimento e progresso. A sua visão tem a ver com um tipo de fluidez, um movimento de vaivém, sem aspirar a qualquer modo específico ou essencial de identidade. 
Nessa perspectiva, também o sociólogo polonês, Bauman (2001), em sua obra Modernidade Líquida, refere-se às atitudes da pós-modernidade. Sugere a existência de um espaço responsável pelo processo de transformação de identidades. Para Bauman (2001), esse espaço destituído de expressões simbólicas de identidade, de relações e de história está impregnado de resíduos necessários ao processo de ir ao encontro do novo.

Entre essas vozes que enaltecem o trânsito, o tempo, o espaço e a fronteira, cada um com sua carga simbólica, suas hierarquias e seus limites, situa-se, mais uma vez, Bhabha, que define uma fronteira não como o ponto em que algo termina, mas "como o ponto onde algo começa a se fazer presente" (BHABHA, 2003, p. 19). Vive-se, atualmente, um momento de trânsito em que espaço e tempo, passado e presente se cruzam para produzir complexas identidades.

\section{Novos modos de ensino e de identidade docente}

Compreender a identidade profissional docente é interpretar a função social dessa profissão e de suas práticas. Para Freitas (2005), "a função social da escola se cumpre na medida da garantia do acesso aos bens culturais, fundamentais para o exercício da cidadania plena no mundo contemporâneo". Para garantir uma formação satisfatória ao educando, diante da sociedade da qual participa, o professor necessita atualizar-se, buscando conhecer melhor as tendências atuais e aplicá-las como alicerce de suas práticas. As mudanças, tanto pessoal, quanto intelectual e profissional das práticas docentes abrangem, segundo a autora, perspectivas individuais e coletivas. As individuais se justificam pelo posicionamento do sujeito de acordo com suas ideologias e crenças; as coletivas se justificam, mais especificamente, pela colaboração e interação entre os grupos e sua flexibilidade em partilhar experiências, sentimentos, fraquezas, habilidades e competências que favoreçam ao social.

Essa análise remete à compreensão de que a mudança passou a ser uma necessidade imprescindível para o exercício da docência, no entanto, deve ser um processo moldado pela transformação, que, no caso do ensino, traduz-se pela aquisição de um processo mais interiorizado de experiências e de motivação para o novo, pois

a maneira de organizar a aula, o tipo de incentivo, as expectativas que depositamos, os materiais que utilizamos, cada uma dessas decisões veicula determinadas experiências educativas, e é possível que nem sempre estejam em consonância com o pensamento que temos a respeito do sentido e do papel que hoje em dia tem a educação (ZABALA, 1998, p. 29).

As discussões que envolvem a necessidade de mudança e de transformação são tema atual em todos os segmentos da sociedade. No caso dos docentes, há o entendimento de que as 
instituições de ensino vêm sendo pressionadas a repensar seu papel diante das transformações que caracterizam o acelerado processo de integração capitalista. Essas transformações decorrem de um conjunto de acontecimentos e de processos que acabam por caracterizar novas realidades sociais, políticas, econômicas, culturais. O que está, então, deslocando as identidades é, segundo Hall (2006, p. 67), “o complexo processo de mudança que atravessa fronteiras nacionais, integrando e conectando comunidades e organizações em novas combinações de espaço-tempo, tornando o mundo mais interconectado".

O que é importante para este estudo quanto ao impacto da tecnologia sobre a identidade é que o tempo e o espaço, conforme indica Hall (2006, p.70), "são também as coordenadas básicas de todo o sistema de representação". Nesse sentido, Carvalho e Simões (2002) em seus estudos, referentes à profissionalização do docente, definem a identidade desse profissional como móvel porque, constantemente, constroem-se valores, crenças, atitudes. As representações veiculadas no papel do docente, então, não estão desvinculadas da produção social e, por isso, são modificadas diante das progressivas mudanças de ordem social.

Apresentar, portanto, uma pesquisa em análise de discurso crítica que traz desabafos em entrevistas realizadas com docentes que compõem um grupo social de uma instituição de ensino em processo de mudança de paradigmas é mostrar a mobilidade da identidade individual e coletiva desses sujeitos.

\section{Compromisso com a Teoria Social do Discurso na perspectiva da Análise de Discurso Crítica}

As relações entre as práticas discursivas e os limites entre essas práticas sociais estabelecidas em uma instituição ou na sociedade mais ampla, segundo Fairclough (2001), são modificadas conforme as direções seguidas pela mudança social. Para maior compreensão dessas relações, recorro à Teoria Social do Discurso (TSD) na perspectiva da Análise de Discurso Crítica (ADC) de Fairclough (2001), que está adequada a este trabalho por trazer propostas de análise da linguagem como prática social.

A ADC preocupa-se com as relações de dominação e de controle e com a forma como elas se estabelecem nos discursos. Nessa perspectiva, Magalhães (2004) lembra que os discursos funcionam como meio de domínio e de força social que serve para legitimar as relações de poder já estabelecidas institucionalmente. Para a ADC, são de grande valor as descrições e a teorização dos processos e das estruturas sociais responsáveis pela produção do fato em si e dos processos 
nos quais os sujeitos são vistos como históricos, criando sentidos em sua interação com a situação.

Assim, as reflexões de Fairclough (2001) nos conduzem à escolha pela teoria que trata das questões do sujeito; pela teoria que o concebe a um só tempo social e singular e que vê o discurso como um objeto historicamente produzido e socialmente interpretado, isto é, o discurso situado no tempo e no espaço. Sob esse enfoque, as estruturas de dominação são legitimadas pela ideologia de sistemas de poder. A ADC, então, é ideal para o nosso objetivo, pois permite identificar como as formas simbólicas foram e continuam a ser utilizadas, a serviço do poder, nas sociedades modernas e nos contextos sociais situados em diferentes aspectos.

Nesse sentido, Fairclough (2003a) traz a ADC como uma ciência crítica concebida como ciência social e destinada a identificar os problemas que as pessoas enfrentam em decorrência de formas particulares da vida social. Igualmente, propõe desenvolver recursos de que as pessoas possam se valer a fim de abordar e de superar esses problemas. Assim, defende o autor, é uma ciência que possibilita ao analista do discurso o acompanhamento da manifestação da linguagem na constituição de identidades, na construção de conhecimento, na organização das instituições sociais e no exercício do poder. A ADC, segundo Fairclough (2003a), incorpora a dimensão do poder como condição de domínio da vida social, demonstrando interesse "pelos modos em que se utilizam as formas linguísticas em diversas expressões e manipulações do poder" (FAIRCLOUGH, 2003a, p. 31).

Além de todas essas características compatíveis com o que se propõe nesta produção, a ADC, como é defendida por Fairclough (2003a), propõe alguns passos: identificar e analisar os elementos que lhe põem obstáculos, mediante a identificação das práticas em que estão localizados; analisar o discurso, abordando aspectos como análise interdiscursiva e as práticas sociais; identificar as possíveis maneiras de superar os obstáculos; refletir criticamente sobre os resultados da pesquisa, visando à maior compreensão das novas concepções de ensino e das exigências quanto à formação docente. Para melhor entendimento, na próxima seção, serão apresentados alguns dos conceitos básicos da ADC.

\section{Discurso como prática social e ideológica}

Discurso, para Fairclough (2001), é tanto um modo de ação das pessoas sobre o mundo e sobre as outras quanto de representação por conduzir uma dialética entre o sujeito e a estrutura social. O discurso é tanto moldado quanto restringido pela estrutura social. "Os eventos discursivos específicos variam em sua determinação estrutural, segundo o domínio social particular ou o quadro institucional em que são gerados" (FAIRCLOUGH, 2001, p. 91). São, 
também, socialmente constitutivos. O discurso é uma prática de representação e de significação do mundo, constituindo e construindo esse mundo em significado.

A relação entre discurso e estrutura social, para o autor, tem natureza dialética, resultando do contraponto entre a determinação do discurso e sua construção social. O discurso é visto como reflexo de uma realidade mais profunda. A constituição discursiva de uma sociedade decorre de uma prática social que está, seguramente, arraigada em estruturas sociais concretas e, necessariamente, é orientada para elas.

Fairclough (2001) defende o discurso como prática política e ideológica. Como prática política, estabelece, mantém e transforma as relações de poder e as entidades coletivas em que existem tais relações; como prática ideológica, constitui, naturaliza, mantém e também transforma os significados de mundo, nas mais diversas posições de poder. A análise de um discurso, tomando como exemplo a prática discursiva, focaliza os processos sociais, por isso, estabelece referência aos ambientes econômicos, políticos e institucionais particulares, nos quais o discurso é gerado. Para Fairclough (2001), os sujeitos podem se contrapor aos discursos estabelecidos e, de forma progressiva, reestruturar a dominação e as formações mediante a prática. Os sujeitos sociais são moldados pelas práticas discursivas, mas, segundo o autor, também são capazes de remodelar e de reestruturar essas práticas.

Enfim, em meio a essa diversidade de concepções, sobressai a abordagem da ADC, que vê o discurso como um momento de prática social, sabendo-se que todas as práticas incluem os seguintes elementos: atividade produtiva, meios de produção, relações sociais, identidades sociais, valores culturais, consciência e semioses, segundo Fairclough (2003a). Esses elementos se acham relacionados dialeticamente.

\section{A questão da identidade}

A questão da identidade tem alcançado maior espaço nos estudos que envolvem a ADC. Tornou-se alvo de discussão entre os analistas do discurso em razão de ser um tema relacionado à origem social, às questões de gênero, de classe, de atitudes, de crenças de um sujeito. É ressaltada a partir das formas linguísticas e dos significados que o sujeito seleciona e expõe, atribuindo-se uma identidade de acordo com as suas relações socioculturais.

O foco de Fairclough (2001 e 2003a) é a mudança discursiva em relação à mudança social e cultural. Dessa forma, as identidades se movem conforme o momento de prática social, que inclui os seguintes elementos: atividade produtiva, meios de produção, relações sociais, identidades sociais, valores culturais, consciência e semioses. Esses elementos se acham relacionados dialeticamente, isto é, não são elementos discretos, embora sejam diferentes. 
Como as mudanças ocorrem nos eventos discursivos, segundo Fairclough (2001), as origens e as motivações imediatas que as geram no evento comunicativo realizam-se nas problematizações das convenções para os produtores ou intérpretes, o que pode ocorrer de diversas formas.

Os produtores enfrentam os dilemas ou problematizações criativamente e, assim, geram mudanças discursivas. Mudanças envolvem formas de transgressão e cruzamento de fronteiras, reunião de representações sociais existentes em combinações com as novas.

Para Chouliaraki \& Fairclough (1999), os avanços na tecnologia da informação subjazem, tanto as transformações econômicas, quanto as culturais, abrindo espaço para novas formas de experiência e de conhecimento; novas possibilidades de relacionamentos via meios de comunicação, tanto impressos, quanto eletrônicos. Estes autores acrescentam que a modernidade fixou-se nos sinais econômicos e culturais que ultrapassam a barreira do tempo e do espaço, tornando possível grande circulação e renovação do conhecimento, bem como novas formas de ação e de interação a distância. Isso quer dizer que a atividade social passou a transcorrer em grandes distâncias espaciais e temporais; indivíduos e grupos vivem relações globalizadas, fazendo uso de recursos tecnológicos em suas práticas locais.

Nesse sentido, Thompson (1995) aponta o avanço no uso das tecnologias e revela que a mídia é um espaço central não só para a difusão da informação renovada, como também para a permanente reconstrução das identidades sociais. Para ele, as experiências vividas permanecem fundamentais, mesmo com a crescente suplementação de situações mediadas pelos discursos que envolvem a mídia, que assume um papel cada vez maior no processo de construção das identidades sociais. Esses discursos são entendidos não só como lugar de reprodução, mas também de construção da vida social. São, portanto, um importante objeto de estudo para melhor compreensão da vida social de grupos específicos, considerando as motivações sociais e os aspectos ideológicos desses mesmos grupos. Assim, a análise que envolve relações sociais e identidades inclui entender-se como é construída a relação entre aqueles que dominam o espaço, a política e a cultura, além de se compreender as relações de poder e de dominação na sociedade.

Adotar práticas com uso das tecnologias não significa o abandono da reflexão teórica, mas é inquestionável que o arsenal tecnológico presente na sociedade da informação tem exigido mudança de hábitos e de atitudes na forma de ensinar. $\mathrm{O}$ que as instituições de ensino superior têm feito diante dessa exigência ainda não supre a insegurança de alguns educadores que argumentam contra a aprendizagem em ambientes cooperativos virtuais. Os discursos acadêmicos apregoam que o conhecimento é complexo, dinâmico, instável e infinito, e os educadores preferem ficar presos às práticas pedagógicas tradicionais. Por isso, configuram-se os entrelugares, em um movimento instável, segundo o conceito de Bhabha. 
Esse movimento chama a atenção. Percebe-se que os professores estão percorrendo um caminho indefinido, um caminho que configura a mobilidade de identidades instáveis, os entrelugares, buscando algo que admita o sentimento de segurança.

\section{O docente universitário nos entrelugares da profissão}

A identidade e a profissionalidade são, portanto, definidas em função do vínculo social que lhes é consubstancial. São afetadas pelas figuras de excesso da "supermodernidade": o tempo, o espaço e a individualização das referências que produzem entrelugares, conforme analisaremos adiante.

Segundo Bhabha (1998), conforme já afirmado nesta pesquisa, a nossa existência hoje é marcada por uma tenebrosa sensação de sobrevivência, de viver nas fronteiras do presente, para as quais parece não haver nome próprio além do atual e controvertido deslizamento do prefixo "pós". Nesse contexto, as interações em sala de aula envolvem uma rede de relações que se entrecruzam de forma dinâmica, na qual são inevitáveis os embates e as ambivalências. Para Bhabha (1998, p.20), os termos do embate cultural são produzidos performaticamente e as ambivalências são perceptíveis nos entrelugares, que são espaços alternativos, criados por embates entre contrários:

É na emergência dos interstícios - a sobreposição e o deslocamento de domínios da diferença - que as experiências intersubjetivas e coletivas de nação [nationnes], o interesse comunitário ou o valor cultural são negociados. De que modo se formam sujeitos nos "entrelugares", nos excedentes da soma das "partes" da diferença (geralmente expressa como raça/classe/gênero etc.)? De que modo chegam a ser formuladas estratégias de representação ou aquisição de poder [empowerment] no interior das pretensões concorrentes de comunidade em que, apesar de histórias comuns de privação e discriminação, o intercâmbio de valores, significados e prioridades pode nem sempre ser colaborativo e dialógico, podendo ser profundamente antagônico, conflituoso e até incomensurável? (BHABHA, 1998, p. 20).

Assim, a força dessas questões é corroborada pela linguagem de crises sociais revestidas por um discurso dominante. "O direito de se expressar a partir da periferia do poder e do privilégio autorizado não depende da persistência da tradição, ele é alimentado pelo poder da tradição" (BHABHA, 1998, p.20). Esse processo, segundo o autor, afasta qualquer acesso imediato a uma identidade original ou a uma tradição recebida, surgindo, assim, os embates de fronteira. Lembra Bhabha que os embates de fronteira acerca do novo: 
[Têm] tanta possibilidade de serem consensuais quanto conflituosos, podem confundir nossas definições de tradição e de modernidade, realinhar as fronteiras habituais entre o público e o privado, o alto e o baixo, assim como desafiar as expectativas normativas de desenvolvimento e progresso. (BHABHA, 1998, p.21).

Nesse sentido, um entrelugar é aqui definido como um sistema de representação um tanto dissociado das condições concretas de existência dos sujeitos que o sustentam.

Para Hall (2006), uma representação é um sistema de significação por meio do qual os processos culturais não podem ser compreendidos quando dissociados dos signos e dos sentidos a eles atribuídos nas relações concretas que os engendram. Para ele, as transformações nas sociedades modernas estão mudando também as nossas identidades pessoais, abalando a ideia que temos de nós próprios como sujeitos integrados. A esse fenômeno, deu o nome de deslocamento e descentração do sujeito. Essa descentração, tanto do mundo cultural, quanto de si mesmo, constitui uma crise de identidade. Nesse sentido, citando Mercer (1990), Hall lembrar que "os estudos da identidade ou a identidade se torna questão quando está em crise, quando algo que supõe como fixo, coerente e estável é deslocado pela experiência da dúvida e da incerteza" (HALL, 2006, p. 9).

No contexto de realização deste trabalho, carregado de tensão, as identidades emergem em um entrelugar, buscando potencializar o processo educativo não presencial e tentando se adaptar ao virtual agora presente. O entrelugar é o espaço físico indefinido dos sujeitos participantes, que, diante do conflito, passam a ocupar lugares desprendidos da territorialidade.

Esse entrelugar, de acordo com Bhabha (1998), configura-se pelas condições e pelos fatores sociais, históricos, econômicos e culturais em ambiente de aprendizagem e em outros espaços para além da sala de aula. É na constituição dos entrelugares que a multiplicidade cultural e social demarca a identidade dos sujeitos, que vai além da identidade individual, ultrapassando a dimensão física e cronológica, atingindo as relações e as condições do contexto local.

\section{Contextualizando a pesquisa}

Esta pesquisa foi realizada em uma instituição de ensino superior particular situada no centro da cidade de Brasília, local em que circula grande número de pessoas que trabalham em empresas do terceiro setor, portanto, funcionários de empresas privadas. É uma faculdade de porte médio, respeitada pelo marketing convincente de ensino de qualidade com uso de metodologia moderna e um quadro de docentes com titulação de mestres e de doutores. 
Apresenta uma estrutura ideal para o ensino diferenciado, com excelentes laboratórios de informática. Possui site próprio, e todos os alunos têm acesso irrestrito à rede. As salas de aula são bem equipadas, a biblioteca possui um acervo diversificado e os equipamentos modernos tornam o ambiente agradável e acolhedor.

A maior parte dos alunos busca a instituição pela localidade. A maioria trabalha em um período e estuda em outro. Residem distante tanto do local de trabalho quanto da faculdade. São jovens que residem em cidades satélites - também denominadas de cidades-dormitórios. O emprego é, em quase todos os casos, de baixa remuneração, portanto, nem todos os alunos possuem computador em casa, porém, têm acesso à internet no local de trabalho e na faculdade. Todos os docentes participantes da pesquisa residem distante da faculdade e enfrentam o cansaço e o acúmulo de aulas em outras instituições de ensino.

Na seção seguinte, apresenta-se o fato que deu origem a este estudo.

\section{O evento: anúncio de mudança}

Como o uso da internet tem sido defendido por pesquisadores da área por ser uma forma ágil de comunicação e ferramenta de estilo moderno de ensino e aprendizagem, ele já se tornou rotina no contexto acadêmico o aluno como forma de se estar em sintonia com o professor. Com auxílio da plataforma de aprendizagem, o professor encaminha os textos ou mesmo trabalhos para serem realizados em casa. O aluno, conhecedor dessa prática, fica sempre atento e, sem se deslocar, cumpre a atividade no tempo previsto. Isso já fazia parte da rotina de muitos professores.

No momento em que os docentes receberam a informação, entretanto, de que a utilização do computador e o ensino a distância seria, a partir de então, uma prática institucionalizada, passaram a vivenciar a insegurança que se assemelha ao que Bhabha (1998) chama de sintoma de vitimização cultural. $\mathrm{O}$ corpo docente passou a conferir ao corpo diretivo a autoridade de poder que emergia naquele momento considerado histórico. Esses docentes deixam, a partir de então, de serem responsáveis pela produção de objetivos, de conteúdos e de métodos a serem trabalhados na plataforma chamada Moodle, para o trabalho, pois todos os conteúdos deviam ser hospedados lá. Eles não estariam mais ao lado do aluno, em sala de aula, toda semana. Além disso, os salários seriam achatados.

A partir daí, o docente passou a ocupar o entrelugar, que pressupõe um sujeito cheio de conflitos e de embate cultural. Da condição de docente revestido de autonomia, passou a dominado, desconectado do passado e do presente. Assim, o professor passou a habitar, de algum modo, além da fronteira entre o tradicional e o moderno. Colocando-se entre a tradição e a 
modernidade, no sentido atribuído por Bhabha (1998) e Augé (2005), viu-se marcado pela insegurança e pela incerteza.

Daí a intenção deste trabalho: colaborar com a necessária transposição desse espaço até então considerado como uma caminhada penosa e inquietante por parte dos docentes. Espera-se contribuir para os debates acerca dos impactos provocados por mudanças culturais e pelas relações de dominação e, ao mesmo tempo, alertar, ao profissional de docência superior, para a busca de um estilo mais crítico em relação à reprodução discursiva e "às práticas discursivas ilegítimas das elites simbólicas" (VAN DIJK, 2008, p. 16) recorrentes no ambiente de ensino.

\section{Composição do corpus}

O corpus deste trabalho foi organizado por alguns fragmentos de entrevista realizada com 20 professores que representam todo o corpo docente do curso de Letras de uma faculdade brasiliense. Entre esses profissionais, apenas seis são do sexo masculino. O objetivo de tais entrevistas é traduzir os discursos com vistas à obtenção de elementos relevantes para a descrição da identidade desses sujeitos sob uma perspectiva crítico-discursiva. Para atender a esse objetivo, buscou-se apreender os significados e as relações sociais estabelecidas nas práticas discursivas do corpo docente, no contexto institucional, e reeditadas nas entrevistas, que serviram de instrumento para a seleção dos recortes para análise.

\section{Analisando os recortes}

Das entrevistas feitas com o corpo docente participante desta pesquisa, destacam-se alguns recortes mais recorrentes para uma ADC (FAIRCLOUGH, 1992, 2003) com o objetivo de se estudar as estratégias e as estruturas de textos a fim de identificar discursos de dominação e de manipulação. Esse enfoque detalha como os modos de representação são legitimados e reproduzidos. É importante, portanto, compreender o papel do discurso na interpretação e na reprodução da dominação e da resistência. Não se trata de mera descrição. Apontam-se recomendações, intervenções práticas e funcionais e conclusões, o que caracteriza um processo viável de pesquisa com realidade social. Quanto à categoria de análise, a escolha feita alia-se à proposta de Fairclough (1992, 2003), que se reporta à análise de identidades sociais afirmando que, para analisar discursos, deve-se considerar, além de outros fatores, a força dos enunciados, a 
coerência, a intertextualidade, a representação dos discursos e a pressuposição. Nesse sentido, os textos foram selecionados em conjunto, como se segue:

\footnotetext{
"Não há mais preocupação com aprendizagem."

"Estamos sendo cada vez mais desvalorizados."

"Não gosto dessa história de computador."

"Com essa forma de ensino, não vão ser bem avaliados."

"O aluno não aprende assim." (Informações verbais) ${ }^{2}$
}

O que ocorre nesses discursos é o que Bhabha chama, em sua obra, de embates de fronteira acerca do que é diferente; do que tem possibilidade de ser, tanto consensual, quanto conflituoso. Esses recortes revelam certa confusão, pois, por eles, os professores demonstram não saber se ficam com o que é tradição ou se adotam o que defendem ser a modernidade. Os docentes mostram-se, nessa ocasião, no entrelugar. Dizer "Não há mais preocupação com aprendizagem" revela ser uma condição própria. O próprio docente anuncia a sua crença.

Considerando que a TSD de Fairclough ensina que os sujeitos fazem suas histórias, produzem os discursos, os sentidos que apresentam nos discursos e as determinações socioideológicas, o participante da pesquisa revela aquele sujeito que não está disposto a mudar e que, consequentemente, não parece preparado para acatar essas novas formas de ensinar. Nesse sentido, é um sujeito que retrata o contexto sociocultural e as várias transformações que ocorrem em seu tempo. Traz, em sua prática, as representações construídas nesse percurso. Sente, portanto, dificuldade de se locomover nesse movimento brusco e demonstra descrença e pouca disposição para buscar novas práticas de ensino.

Nos discursos de outros seis professores, tem-se:

\footnotetext{
"Essas inovações são muito importantes, mas acho que os alunos não estão preparados."

“Os alunos não estão preparados."

"Inovações são sempre bem-vindas, mas assim é difícil."

"Prefiro a sala de aula normal."

"É importante saber pesquisar na Internet."

“Aluno não gosta de estudar, assim só piora a situação.” (informações verbais) ${ }^{3}$
}

Nesses discursos, os professores adotam a reificação dos discursos já cristalizados socialmente. Apontam conhecimento da importância do uso dos computadores no ensino, mas a preferência é pela aula tradicional, que chamam de "sala de aula normal". Ao mesmo tempo,

\footnotetext{
${ }^{2}$ Declarações obtidas por meio de entrevistas orais com os professores.

${ }^{3}$ Idem.
} 
culpam o aluno pelo despreparo, mas, em momento algum, demonstram interesse ou possibilidade de serem participativos no processo de inovação. Essa é a posição de entrelugar dos docentes. As afirmações sugerem sujeitos desconexos entre o passado e o presente, vivendo, de algum modo, além da fronteira, mas entre a tradição e a modernidade. No sentido atribuído por Augé (2005), são profissionais marcados pela insegurança e pela incerteza: gostam do novo, porém, sequer demonstram desejo de aprender a lidar com a mudança. Acomodam-se e eximemse, assim, de suas responsabilidades individuais, repetindo que "o aluno não gosta de estudar".

Comentários adicionais elucidam ainda melhor a condição de entrelugar do professor no processo de ensino da instituição:

\footnotetext{
"Tenho muita dificuldade de conciliar o tempo para responder os e-mails dos alunos."

"Há necessidade de mais treinamentos para aprendizagem do uso da ferramenta."

"É uma ferramenta importante, mas..."

“Os próprios professores não sabem usar o computador."

“O aluno só usa bem o MSN.” (informações verbais) ${ }^{4}$
}

Ao mesmo tempo, as observações feitas pelos entrevistados podem revelar insegurança quanto ao resultado do trabalho, apesar de terem adotado o discurso de reconhecedores da riqueza desse investimento para a formação do aluno. Parecem descrentes e sentem-se desamparados. Reconhecem, no entanto, a necessidade de maior preparo. Esses discursos demonstram a situação de entrelugares. Os profissionais confirmam, em suas respostas, que a identidade do professor está em movimento, conforme explica Bhabha, pela sobremodernidade de Augé e pelo movimento contínuo da modernidade líquida de Bauman. Reconhecem a constante necessidade de reconstrução de valores e de atitudes em relação à profissionalização, mas se utilizam do conectivo de oposição - "mas" - e do verbo na terceira pessoa - "não sabem" -, como se eles mesmos estivessem ausentes desse contexto. Demonstram, assim, a constituição de um sujeito cheio de incertezas.

Ao ser questionado sobre a facilidade e a satisfação em relação ao uso da plataforma adotada - Moodle -, um professor responde de forma bem descontraída e até demonstra, no seu discurso, uma insinuação de revolta: "Só aumenta o trabalho da gente" (informação verbal) 5 .

Cabe aqui a reflexão sobre o discurso que, segundo Fairclough (2001), sugere uma identidade estruturada e que subjaz aos eventos discursivos e não à formação individual. Esse é um modelo discursivo já cristalizado no meio acadêmico e, muitas vezes, não revela a atitude do

\footnotetext{
${ }^{4}$ Declarações obtidas por meio de entrevistas orais com os professores.

${ }^{5}$ Declaração obtida por meio de entrevistas orais com os professores.
} 
sujeito que o reproduz. Segundo Fairclough, muitos eventos discursivos manifestam uma orientação existente, uma orientação construída pelo código de uma categoria social especifica.

As transformações e as exigências chegaram como uma causa para o grupo de docentes se situar em entrelugares. Assim, fica mais simples a continuidade do discurso. As pessoas costumam usar as opiniões pessoais e, às vezes, expressam-nas como se fossem coletivas. Isso ocorre no caso desse professor ao usar a expressão "da gente". Ele parece desanimado com as inovações e com a necessidade evidente de atualização, que faz parte das atribuições da profissão professor.

Após conhecer melhor o processo, segundo Bhabha (1998), "os sujeitos costumam mudar de opinião". Como exemplo, em nova questão sobre a continuidade do uso da plataforma, o mesmo professor acredita que "com o tempo, vai se acostumar e aprender a gostar" (informação verbal) ${ }^{6}$. A explicação vista desse entrelugar e de que o tempo vai preencher esse espaço demonstra a relação entre tempo e espaço apresentada por Augé (2005).

Todas as respostas destacadas revelaram que os participantes se constituem como profissionais do ensino superior e que vivenciam a condição de entrelugares, pois se sentem surpresos e não prontos para a demanda de uso da tecnologia, imposta pela modernização do ensino. Esse é o contexto sócio-histórico e político-institucional, marcado por mudanças e paradoxos no desenvolvimento. Desconcertados, os professores não participam das decisões ideologicamente tomadas pela elite institucional.

A ADC lida com esses aspectos relacionados ao poder, à dominação. Encontram-se, aqui, não apenas reflexos da realidade, mas também discursos moldados por forças políticas, econômicas e culturais. Em todos os casos, o poder e a dominação estão associados a imperialismos específicos, ligados ao ensino e às elites que definem as regras, a rotinas que formam a base da reprodução discursiva cotidiana de poder nesses domínios e instituições.

O que aconteceu, de fato, limita-os como sujeitos não autores de seus discursos e de suas vontades. Carregam as representações anteriormente construídas, revestem-se de insegurança e incertezas quanto às inovações para o ensino mediadas pelo uso de tecnologias. Os professores encontram-se, assim, entrelugares, em movimento contínuo e, segundo Bhabha (1998), esse é um processo sócio-histórico que, ora satisfaz, ora não satisfaz. No desenvolvimento das atividades docentes mediadas pela Internet, os educadores visualizam fatos que geram sentimentos que, ora os levam a um profundo desconforto; ora, à plena euforia.

Enfim, esses professores estão no entrelugares, situação que permite percursos, passagens, intercâmbios, compartilhamento e que não esconde apenas leis de um lugar próprio

\footnotetext{
${ }^{6}$ Idem.
} 
individual e solitário. Para que o professor possa interagir e para que alcance algum benefício, é necessário ocupar um espaço em que possa ser concebido, e não um lugar por onde o discurso apenas passa.

O entrelugar ocupado por esses sujeitos é permeado de incertezas, mas, ao mesmo tempo, promissor. Oferece oportunidades ao professor para trilhar caminhos que podem ser transformados em possibilidades emancipatórias. Para que o professor possa ocupar um lugar próprio de um sujeito revestido de capacidade de estabelecer-se em um espaço de compartilhamento, é necessário, então, ser um profissional que interage de forma crítica. É preciso ser porta voz de um discurso emancipatório e estar receptivo aos novos paradigmas de ensino exigidos pelo atual contexto sociocultural, imposto pela modernidade.

\section{Algumas considerações}

A análise empreendida sugere reexame sobre as concepções de ensino e de utilização de novas tecnologias, indicando a necessidade de uma reflexão acerca dos discursos que colaboram para a mobilização e a instabilidade da identidade do professor que se pôs entrelugares, segundo os preceitos de Bhabha (1998).

Fatores como, por exemplo, a escassa formação continuada, as múltiplas exigências extraclasse, a excessiva regulamentação e o controle e a perda de autonomia afetam o papel social e, consequentemente, a identidade do professor, que constrói valores, crenças, atitudes em função desse determinado eixo pessoal e profissional. O professor situado entrelugares sente grande impacto cultural ao se deparar com a necessidade de desenvolver atividades docentes que exigem novos paradigmas, principalmente quando se trata de recursos tecnológicos. Os professores demonstram sentimento de profunda insegurança, entretanto, nesse mesmo entrelugar, percebem que existem oportunidades de trilhar caminhos que podem ser transformados em possibilidades emancipatórias para o seu fortalecimento como sujeito social capaz de interagir no coletivo onde sua atuação é verificável. Os professores demonstram sentimento de insegurança, entretanto, nesse mesmo entrelugar, percebem que existem oportunidades de trilhar caminhos que podem ser transformados em possibilidades emancipatórias para o seu fortalecimento como sujeito social capaz de interagir no coletivo onde sua atuação é verificável.

As práticas discursivas podem se tornar contraditórias de acordo com as circunstâncias sociais do sujeito, variando entre relativamente fortes ou fracas, dependendo da articulação no momento atual. Assim, os elementos podem ser descontínuos e bem definidos ou pouco nítidos e 
mal definidos. Nesse caso, de acordo com os estudos de Fairclough (2001), o sujeito entrevistado lança mão de um discurso historicamente construído, transformando o passado e as convenções existentes, ocupando, assim, no presente, segundo Bhabha, o entrelugar. O perfil desse docente revela-se sentimento de quem se sentia solitário, sem argumentos para fortalecimento de seu novo papel de professor. Nesse aspecto, a questão do entrelugar alia-se à TSD, que propõe a mudança social e política como significativa para um processo de mudança cultural e social. A TSD aponta para situações nas quais as mudanças ocorrem nos eventos discursivos. Segundo Fairclough (2003a), existem as origens e as motivações imediatas que geram essas transformações.

Nesse contexto, o docente revela estar entre um jogo dramático de vozes que torna multidimensional a representação socialmente constituída e que, sem buscar uma síntese de conjunto, cria uma tensão dialética que configura a arquitetura própria de seu discurso. Ele, consequentemente, não encontra um lugar seguro para a constituição de sua subjetividade. Seu discurso revela comportamentos impregnados de significados e confirmam que o processo de mudança não ocorre de forma passiva entre o grupo, que está no entrelugar, segundo Bhabha (1998). Dessa forma, nessa condição, anular o diálogo e a reconstrução possível de sentidos seria como fechar o acesso ao que poderia ser completado. Agindo assim, os professores não se tornam sujeitos participantes do processo.

Os professores participantes desta pesquisa enfrentam os dilemas que podem gerar mudanças discursivas. As mudanças que ora devem surgir envolvem formas de transgressão e de cruzamento de fronteiras. Para essa transposição, é preciso árdua afluência de representações sociais existentes em combinações com as novas. Em contínuo movimento, esses docentes deparam-se com fatores que interferem de forma contrária ao bom exercício de sua profissão, como problemas nas relações de trabalho, perda de autonomia, corte de regalias para contenção de custos da instituição, insegurança quanto à permanência no quadro e, além disso, dificuldades ao lidar com as inovações tecnológicas idealizadas pela mantenedora. Esses problemas acarretam baixa autoestima e consequente diminuição da qualidade de vida. São fatores que confirmam que a identidade do professor é afetada pelo prefixo "pós" apontado por Bhabha, pela sobremodernidade, pelo movimento contínuo da modernidade líquida de Bauman. É constante a necessidade de reconstrução de valores e de atitudes em relação à profissionalização, determinando, assim, um sujeito cheio de incertezas.

Por fim, o que ocorre com o corpo docente nesse novo contexto? Ele situa-se no entrelugares. Faz parte de uma construção instável que impregna aquela identidade que era e, ao mesmo tempo, aquela que não é, mas que poderia ser, revelando-se indeterminado e pertencente a um sistema ideológico de mercado e de poder. 


\section{Referências}

AUGÉ, M. Não-lugares: introdução a uma antropologia da supermodernidade. (Tradução Maria Lucia Pereira). 4. ed.. Campinas: Papirus, 2004. BAUMAN, Z. Modernidade Líquida. Tradução: Plinio Dentzien. Rio de Janeiro: Ed. J. Zahar, 2002.

BAUMAN, Z. Identidade : Entrevista a Benedetto Vecchi. tradução, Carlos Alberto Medeiros. - Rio de Janeiro: Ed. J. Zahar, 2005.

BHABHA, H. K. O local da cultura. Belo Horizonte: Editora da UFMG, 1998, 2003.

CARVALHO, J.; SIMÕES, R. H. S. Identidade e profissionalização docente: um retrato delineado a partir dos periódicos nacionais. In: ANDRÉ, Marli Elisa (org.). Formação de professores no Brasil (1990-1998). Brasília: MEC/INEP/COMPED, p. 185-204 (Série Estado do Conhecimento, $\mathrm{n}^{\circ}$ 6), 2002.

CHOULIARAKI, L.; FAIRCLOUGH, N. Discourse in late modernity. Rethinking critical discourse analysis. Edinburgh: Edinburgh University Press, 1999.

FAIRCLOUGH, N. Language and power. New York: Longman, 1989.

Discurso e mudança social. Tradução de Izabel Magalhães. Brasília: Editora Universidade de Brasília, 2001 [1992].

A Análise Crítica do Discurso e a mercantilização do discurso público: as universidades. In: MAGALHÃES, Célia. (Org.). Reflexões sobre a Análise Crítica do Discurso. Belo Horizonte: Faculdade de Letras, UFMG, 2001.

Analyzing discourse: textual analysis for social research. London: Routledge, 2003a.

El análisis crítica del discurso como método para la investigación en ciências sociales. In: WODAK, R.; MEYER, M. (Comp.). Métodos de Análisis Crítico del Discurso. Traducción de Tomáz F. Aúz y Beatriz Eguibar. Barcelona: Gedisa, 2003 b.

FREITAS, L. C. de. Mudanças e inovações na educação. 2. ed. São Paulo: Edicon, 2005.

HALL, S. A identidade cultural na pós-modernidade. Tradução: SILVA, T.; LOURO, G.L. 11. ed. Rio de Janeiro: DP\&A. 2006.

SILVA, T. T. (org.). Identidade e diferença: a perspectiva dos estudos culturais. 2. ed. Petrópolis: Vozes, p. 103-133, 2002.

SILVA, T. T. (org. ) O sujeito da Educação: Estudos Foucautianos. Petrópolis, RJ: Vozes, 1994.

THOMPSON, J. B. Ideologia e cultura moderna: teoria social crítica na era dos meios de comunicação de massa. Petrópolis, RJ: Vozes, 1995.

VAN DIJK, T. A. Discurso e poder; HOFFNAGEL, J; FALCONE, K (org.). Contexto. São Paulo, 2008.

ZABALA, A.. A prática educativa: como ensinar. trad. ROSA, E.F.F. Porto Alegre: ArtMed, 1998. 